\title{
Weighted Product dalam Sistem Pendukung Keputusan untuk Penentuan Mustahik
}

\author{
Raden Aulia Rahman ${ }^{1}$, Meinarini Catur Utami², Elvi Fetrina ${ }^{3}$
}

\begin{abstract}
Abstrak-Dana zakat pada lembaga Yayasan Qurrota Ayuni diberikan kepada mereka yang memang membutuhkan dan tergolong ke dalam mustahik. Permasalahan yang sering dijumpai adalah proses pemilihan yang begitu lama dan adanya kesalahan hitung sehingga menyebabkan hasil seleksi mustahik kurang akurat. Untuk mendapatkan zakat tersebut maka harus sesuai dengan aturan-aturan dan kriteria-kriteria yang telah ditetapkan. Aturan-aturan dan kriteria-kriteria tersebut membuat tidak semua yang mendaftar sebagai mustahik dapat diterima. Adanya jumlah pendaftar penerima zakat yang begitu besar maka perlu adanya sistem pendukung keputusan yang dapat membantu menentukan mustahik yang berhak dan diutamakan untuk dapat menerima zakat dengan menggunakan metode Weighted Product. Adapun tools yang digunakan yaitu Php dan MySql serta UML sebagai metode pembuatan sistem. Hasil penelitian ini berupa sistem pendukung keputusan yang bisa menentapkan mustahik yang berhak untuk dapat menerima zakat dengan lebih cepat waktunya dan lebih objektif.
\end{abstract}

Keywords - Mustahik, Sistem Pendukung Keputusan, Weighted Product.

\section{PENDAHULUAN}

Z akat merupakan salah satu dari rukun Islam di mana setiap manusia yang memiliki harta kekayaan telah mencapai nisab dan haul (satu tahun kepemilikan) berkewajiban untuk mengeluarkan zakat. Sebagian harta yang kita miliki merupakan hak orang lain, sebab itu kita harus mengeluarkan zakat untuk orang lain menerima haknya kembali. Tujuan zakat yaitu untuk membersihkan harta kita. Mengeluarkan zakat semata-mata bentuk cerminan keimanan kita sebagai orang muslim. Selain itu pemberian zakat ialah untuk membantu meringankan beban para penerima zakat, dan juga sebagai tali persaudaraan antara yang memberi zakat dengan yang menerima zakat.

Received: 2 Agustus 2019 Revised: 8 Juli 2020; Accepted: 8 Juli 2020

${ }^{1}$ R.A Rahman, Prodi Sistem Informasi Fakultas Sains dan Teknologi UIN Syarif Hidayatullah Jakarta, Indonesia (e-mail: radenauliarahman@gmail.com).
Zakat merupakan suatu ibadah yang paling penting kerap kali dalam Al-Qur'an, Allah menerangkan zakat beriringan dengan menerangkan Shalat yang berarti mempunyai hubungan yang rapat sekali dalam hal keutamaannya. Dan dirikanlah sembahyang dan berikanlah zakat [1], Sesungguhnya beruntunglah orang-orang yang beriman, yaitu orang-orang yang khusyuk dalam sembahyangnya, dan orang-orang yang menjauhkan diri dari (perbuatan dan perkataan) yang tiada berguna ,dan orang-orang yang mengeluarkan zakat [2].

Referensi [3] dapat diterjemahkan sebagai berikut: "Sesungguhnya zakat itu hanyalah untuk orang-orang fakir, orang miskin, amil zakat, yang dilunakkan hatinya (mualaf), untuk (memerdekakan) hamba sahaya, untuk (membebaskan) orang yang berhutang, untuk jalan Allah, dan untuk orang yang sedang dalam perjalanan, sebagai kewajiban dari Allah. Allah Maha Mengetahui, Maha Bijaksana”.

Masalah yang sering terjadi di dalam masyarakat kita adalah kepada siapa zakat seharusnya diberikan. Apakah lebih utama zakat diberikan langsung kepada orang yang berhak, atau melalui lembaga zakat. Biasanya ada perasaan puas dan tenang jika menyaksikan secara langsung penyaluran zakat kepada mereka yang dianggap berhak menerimanya. Tapi terkadang penyaluran langsung yang dilakukan oleh orang yang ingin memberi zakatnya tidak tepat mengenai sasaran. Terkadang orang sudah merasa memberikan zakatnya kepada mustahik, padahal ternyata yang menerima bukanlah mustahik yang sesungguhnya, hanya karena kedekatan hubungan maka ia memberikan zakatnya. Misalnya saja zakat diberikan kepada kerabatnya, yang menurutnya kerabatnya adalah orang yang pantas mendapatkan zakat dan masuk dalam kategori mustahik, padahal jika dibandingkan dengan orang yang berada di sekitar lingkungannya masih banyak orang yang lebih berhak untuk mendapatkan zakatnya karena lebih menderita, dan tidak mampu dibandingkan dengan kerabatnya tersebut.

Sistem pendukung keputusan (SPK) dimaksudkan untuk menjadi alat bantu bagi para pengambil keputusan untuk memperluas kapabilitas mereka, namun tidak untuk menggantikan penilaian mereka [4]. Adapun Weighted Product

${ }^{2}$ M.C Utami, Prodi Sistem Informasi Fakultas Sains dan Teknologi UIN Syarif Hidayatullah Jakarta, Indonesia (e-mail: meinarini@uinjkt.ac.id).

${ }^{3}$ E. Fetrina, Prodi Sistem Informasi Fakultas Sains dan Teknologi UIN Syarif Hidayatullah Jakarta, Indonesia (e-mail: elvifetrina@uinjkt.ac.id) 
(WP) merupakan salah satu metode yang digunakan untuk menyelesaikan masalah pengambilan keputusan. Metode WP menggunakan perkalian untuk menghubungkan nilai atribut (kriteria), di mana nilai setiap atribut (kriteria) harus dipangkatkan dulu dengan bobot atribut (kriteria) yang bersangkutan. Metode WP sudah banyak yang menerapkannya, di antaranya yaitu [5] dan [6]. Implementasi WP untuk memilih penerimaan beasiswa prestasi dan hasilnya yaitu penyelesiaan penerimaan beasiswa prestasi lebih cepat terlaksana [5]. Selain itu, WP digunakan untuk memilih smartphone android dan hasilnya yaitu adanya aplikasi yang memudahkan bagi calon pembeli handphone [6]. Adapun metode untuk develop sistemnya menggunakan UML (Unified Modelling Language) dimana pernah digunakan untuk menentukan besaran remun dosen di UIN Sumatera Utara Medan [7]. Hasil yang didapat yaitu terciptanya blueprint model perancangan sistem informasi remunerasi dosen UIN Sumatera Utara Medan. Selain itu UML juga digunakan untuk membangun Sistem Informasi monitoring penjualan dan stok barang di Distro Zhezha Pontianak [8]. Perancangan SPK ini juga menggunakan PHP yang mana juga sudah banyak yang menerapkan yaitu menggunakan PHP untuk pembuatan sistem informasi perpustakaan online berbasis web. Hasilnya yaitu aplikasi yang dapat membantu proses pencatatan dengan otomatisasi peminjaman, pengembalian, permintaan peminjaman serta membantu mempercepat proses pencarian buku untuk anggota perpustakaan [9].

Adapun tujuan penelitian ini adalah menentukan mustahik dengan metode WP dalam system pendukung keputusan di Yayasan Qurrota Ayuni.

\section{KAJIAN PUSTAKA}

\section{A. Sistem Pendukung Keputusan}

Sistem Pendukung Keputusan (SPK) atau Decision Support System (DSS) merupakan sebuah sistem yang menyediakan informasi yang dapat membantu para pengambil keputusan membuat keputusan [4] serta bisa memadupadankan sumber daya intelektual dari individu dengan bantuan komputer guna mengambil keputusan. SPK biasanya untuk mendukung level manajemen dalam melakukan pekerjaan yang bersifat analisis pada situasi yang kurang terstruktur dengan kriteria yang kurang jelas [10].

\section{B. Weighted Product}

Weighted Product adalah sebuah metode yang menggunakan perkalian dalam mengkoneksikan rating atribut, di mana rating setiap atribut harus dipangkatkan dulu dengan bobot atribut yang bersangkutan [11]. Mekanisme ini serupa dengan skema normalisasi. Preferensi untuk alternatif $S_{i}$ diberikan seperti dalam persamaan:

$$
S_{i}=\prod_{j=1}^{n} x_{i j}^{w_{j}}
$$

dengan $i$ adalah nilai $1,2,3, \ldots, m ; j$ adalah nilai dari $1,2, \ldots$, $n$ dan $\sum w_{j}=1$. Dengan $S_{i}$ adalah preferensi alternatif dianalogikan sebagai vektor $S$, di mana $x$ adalah nilai kriteria, $n$ adalah jumlah alternatif, dan $w_{j}$ adalah bobot kriteria, bernilai positif untuk kriteria keuntungan dan bernilai negatif untuk kriteria biaya.

Algoritma dari model Weighted Product ini adalah sebagai berikut:

1. Melakukan perbaikan bobot terlebih dahulu agar total bobot $\sum w_{j}=1$. Caranya dengan membagi nilai bobot dengan penjumlahan seluruh nilai bobot.

2. Mengalikan seluruh atribut untuk sebuah alternatif dengan bobot sebagai pangkat positif untuk atribut keuntungan dan bobot pangkat negatif pada atribut biaya disebut vektor $S_{i}$.

3. Hasil perkalian dijumlahkan untuk menghasilkan nilai pada setiap alternatif.

4. Melakukan pembagian antara $S_{i}$ dan hasil penjumlahan $S_{i}$ $\left(\sum S_{i}\right)$ yang akan menghasilkan nilai referensi $V_{i}$.

5. Ditemukan urutan alternatif terbaik yang akan menjadi keputusan.

\section{Zakat}

Referensi [12] menyatakan tentang pengelolaan zakat, zakat adalah harta yang wajib disisihkan oleh seorang muslim atau badan yang dimiliki oleh orang muslim sesuai dengan ketentuan agama untuk diberikan kepada yang berhak menerimanya. Sedangkan Muzakki adalah orang atau badan yang dimiliki oleh orang muslim yang berkewajiban menunaikan zakat serta Mustahik adalah orang atau badan yang berhak menerima zakat.

\section{Mustahik}

Mustahik adalah orang atau badan yang berhak menerima zakat. Mustahik delapan ashnaf ialah fakir, miskin, amil, mualaf, riqab, gharim, shabilillah, dan ibnu sabil yang di dalam aplikasinya dapat meliputi orang-orang yang paling tidak berdaya secara ekonomi seperti anak yatim, orang jompo, penyandang cacat, orang yang menuntut ilmu, pondok pesantren, anak terlantar, orang yang terlilit utang, pengungsi yang terlantar dan korban bencana alam.

Referensi [13] menjelaskan kedelapan golongan penerima zakat, sebagai berikut:

1. Fakir

Orang yang tidak memiliki harta dan tidak mempunyai penghasilan layak yang memenuhi kebutuhan makan, pakaian, perumahan dan kebutuhan primer lainnya.

\section{Miskin}

Orang yang memiliki harta dan mempunyai harta yang layak baginya, tetapi penghasilannya belum cukup untuk keperluan minimum bagi dirinya dan keluarga yang menjadi tanggung jawabnya.

3. Amil Zakat

Mereka yang melaksanakan kegiatan pengumpulan dan pendayagunaan zakat termasuk administrasi pengelolaan.

4. Mualaf

Golongan yang perlu dilunakkan hatinya kepada Islam atau untuk lebih memantapkan keyakinan kepada Islam.

5. Riqab

http://journal.uinjkt.ac.id/index.php/aism 
Pembebasan budak dan usaha menghilangkan segala bentuk perbudakan.

\section{Gharimin}

Gharimin adalah orang yang mempunyai hutang untuk kemaslahatan umat maupun masyarakat dalam melaksanakan ketaatan dan kebaikan.

7. Fisabilillah

Usaha dan kegiatan perorangan atau badan yang bertujuan untuk menegakkan kepentingan agama atau kemaslahatan umat.

\section{Ibnu Sabil}

Orang yang kehabisan bekal dalam melakukan perjalanan melintas dari satu daerah ke daerah lain demi kemaslahatan umat dan agama Islam.

\section{E. Metode Pengembangan Sistem}

Dalam penyusunan penelitian ini, metode pengembangan yang digunakan adalah metode berorientasi objek dengan model pengembangan Rapid Application Development (RAD) menggunakan tools Unified Modeling Language (UML). Metode RAD yang dipakai penulis memiliki tahapan-tahapan berikut: [14]

1. Requirement Planning

Berdasarkan observasi, wawancara, studi pustaka dan studi literatur sejenis. Tahap ini terdapat beberapa langkah yang dilakukan dalam mengidentifikasi kebutuhan dan tujuan dari sistem yang akan dibangun. Ada dua tahap yaitu:

a. Analisis sistem berjalan, yang terdiri dari sistem sedang berjalan dengan membuat rich picture dan mengidentifikasi masalah.

b. Analisis sistem usulan, yang terdiri dari pemecahan masalah dan menggambarkan sistem usulan dengan rich picture.

2. Workshop and Design

Tahap lanjutan dari tahap requirment planning, maka pada tahap ini penulis melakukan perancangan sistem menggunakan tools UML (unified Modelling Language) sesuai dengan kebutuhan dan tujuan yang sudah diidentifikasi pada tahap requirment planning. Tahapan yang dilakukan pada tahap perancangan sistem ini adalah sebagai berikut:

a. Membuat Use Case Diagram

b. Membuat Skenario Use Case

c. Membuat Activity Diagram

d. Membuat Sequence Diagram

e. Membuat Class Diagram

3. Implementation

Tahap ini terdiri atas dua tahapan, yaitu tahap pengimplementasian sistem ke dalam bahasa pemrograman (Coding) dan tahap pengujian sistem. Pada tahap ini sistem yang dibangun dengan menggunakan bahasa pemrograman PHP dan MySQL untuk databasenya. Sedangkan tahap pengujian sistem dengan menggunakan metode blackbox testing, dimana para pengguna sistem melakukan input data pada sistem dan melihat output dari sistem apakah sesuai dengan sistem yang diharapkan.

\section{Metode Penelitian}

Peneliti mengunjungi Yayasan dengan pengamatan langsung proses kegiatan di Yayasan Qurrota Ayuni selama 26 hari dari tanggal 1 Juni 2017 hingga 1 Juli 2017. Pengamatan dilakukan untuk mengetahui proses pendaftaran calon mustahik, kelengkapan data calon, survei, penyaluran zakat, wawancara dengan calon mustahik. Wawancara dengan mengadakan tanya jawab dengan Ibu Neneng Nurul Hasanah selaku Sekretaris Yayasan Qurrota Ayuni pada tanggal 1 dan 9 Juni 2017 di Serpong Tangerang Selatan Banten. Wawancara dilakukan untuk mengetahui permasalahan sistem berjalan penentuan mustahik. Tahap pengembangan sistem mengacu pada pengembangan $\mathrm{RAD}$, di mana pada bagian implementation, meliputi interface, perangkat lunak, instalasi perangkat keras, dan pengujian sistem.

\section{HASIL DAN PEMBAHASAN}

\section{A. Analisis Sistem Berjalan}

Yayasan Qurrota Ayuni mempunyai bagian khusus yang menangani pemberian dana zakat kepada mustahik zakat yaitu bagian pendayagunaan zakat. Gambar 1 ini adalah alur proses pengajuan mustahik untuk diterima sebagai mustahik di Yayasan Qurrota Ayuni.

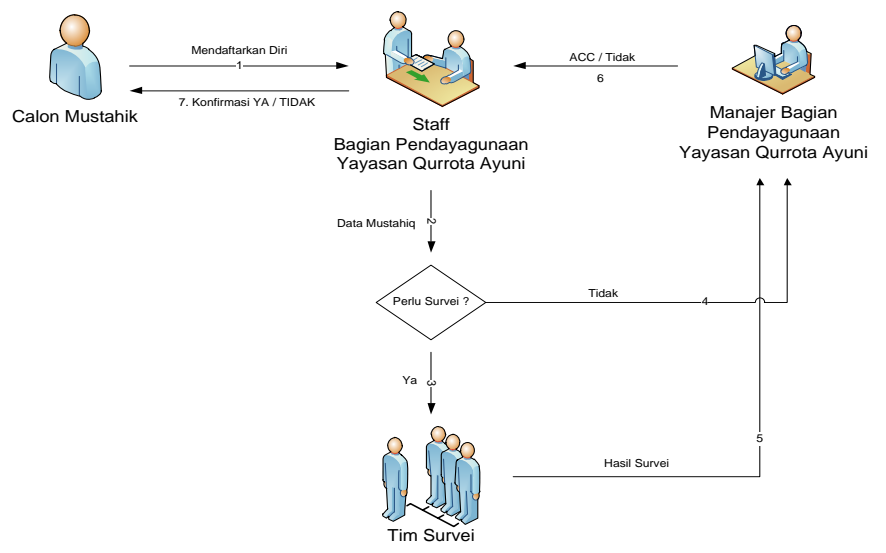

Gambar 1. Analisis sistem berjalan

\section{B. Analisis Sistem Usulan}

Sistem yang penulis ingin buat adalah sebuah sistem pendukung keputusan penentu mustahik yang bertujuan membantu menyelesaikan masalah yang ada pada Yayasan Qurrota Ayuni yaitu:

1. Sistem dapat menentukan mustahik yang tepat.

2. Sistem dapat menentukan perbandingan kelayakan mustahik dengan perankingan mustahik yang nantinya berguna untuk menyeleksi alternatif pemilihan mustahik yang diutamakan.

Gambar 2 menunjukkan gambaran sistem baru yang ingin penulis implementasikan pada proses penentuan mustahik di Yayasan Qurrota Ayuni. 


\section{Perhitungan SPK dengan Weighted Product}

Aliran proses sistem pendukung keputusan dengan menggunakan metode weighted product adalah ditunjukkan pada Gambar. 3.

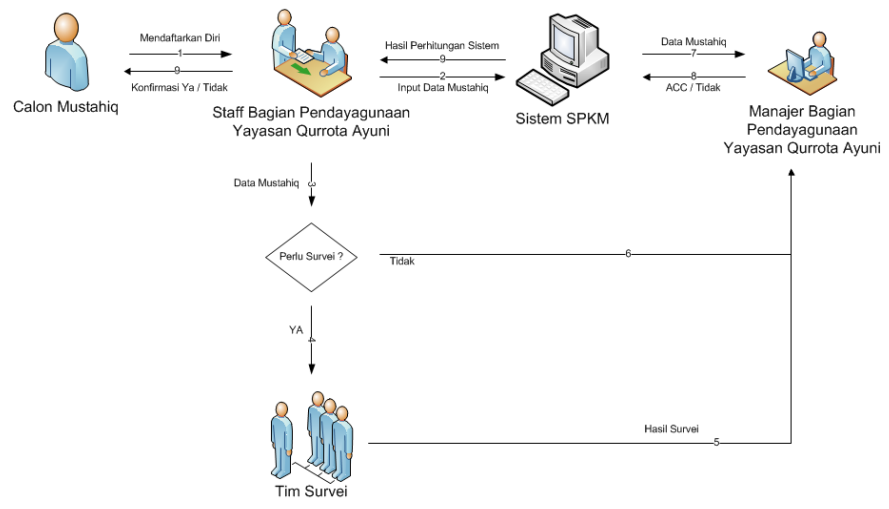

Gambar 2. Analisis sistem usulan

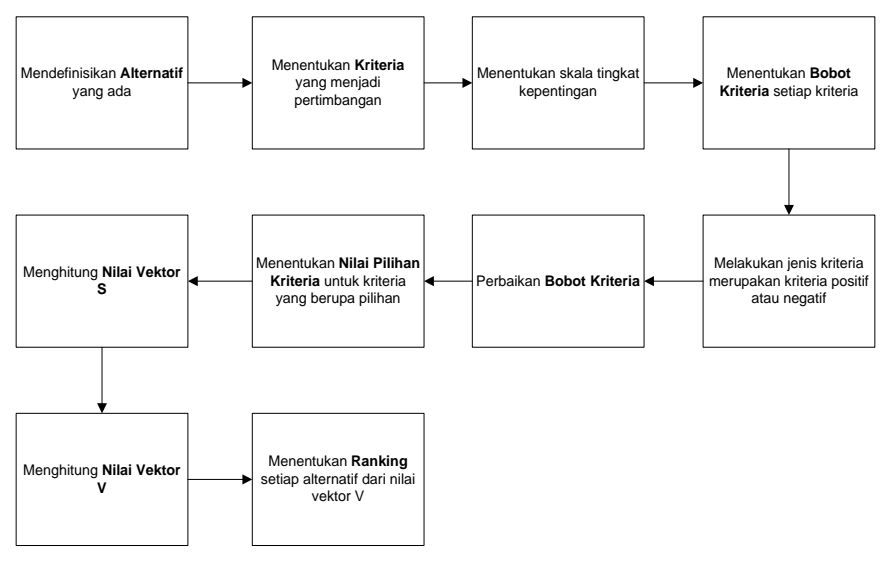

Gambar 3. SPK dengan metode weighted product

\section{Use case Diagram}

Pada use case diagram yang digunakan dalam sistem pendukung keputusan penentu mustahik terdapat 2 aktor yang memiliki beberapa tugas yang harus dilakukan (Gambar 4.).

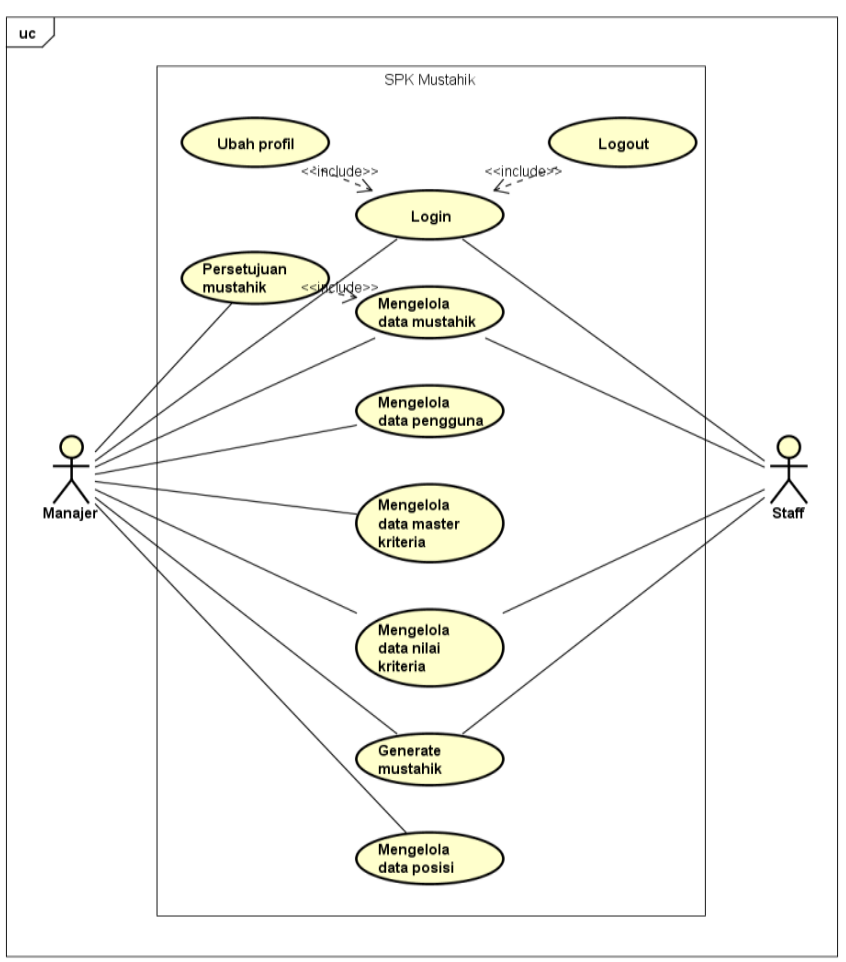

Gambar 4. Use Case Diagram

E. Activity Diagram

Berikut potongan dari berbagai macam activity diagram. Pada Gambar 5. memperlihatkan diagram Generate Mustahik.

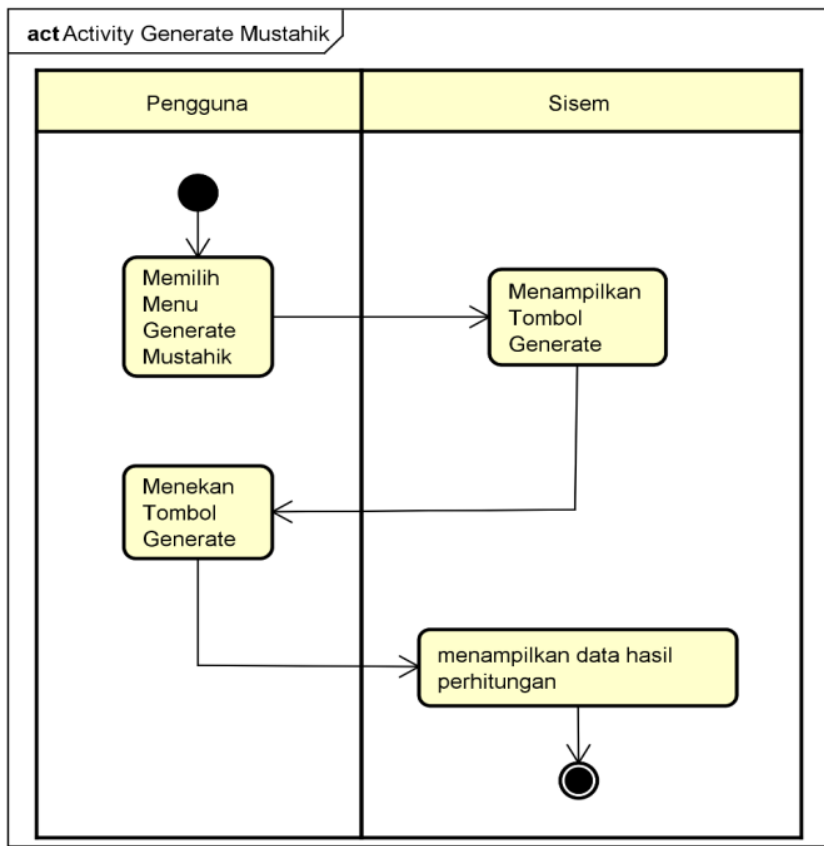

Gambar 5. Activity diagram 


\section{F. Sequence Diagram}

Gambar 6 adalah potongan dari berbagai macam sequence diagram, yaitu merupakan diagram proses login.

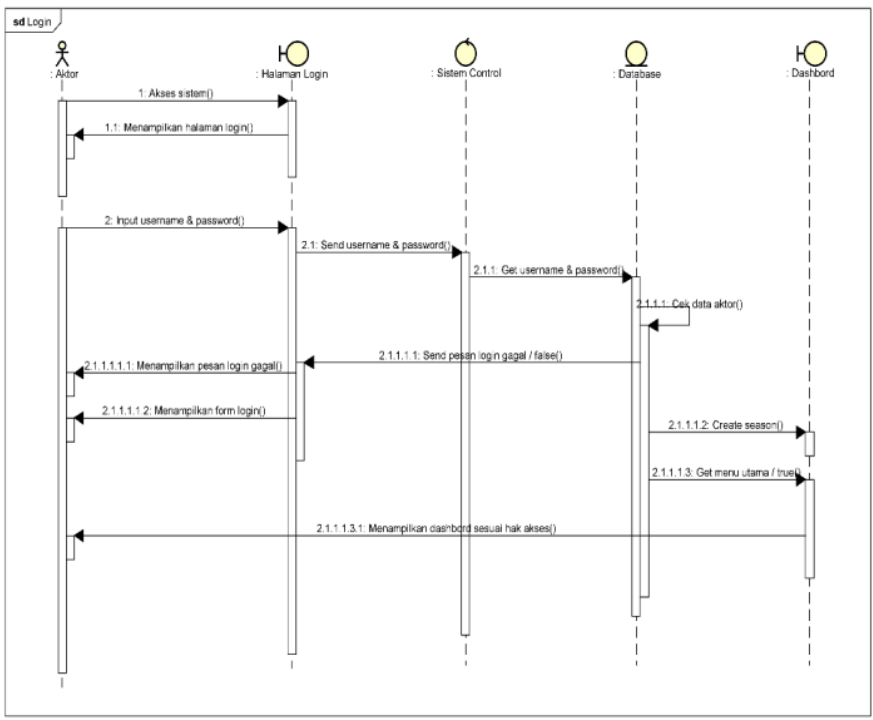

Gambar 6. Sequence diagram

\section{G. Class Diagram}

Class Diagram pada Sistem Pendukung Keputusan Penentu Mustahik dapat dilihat pada Gambar. 7.

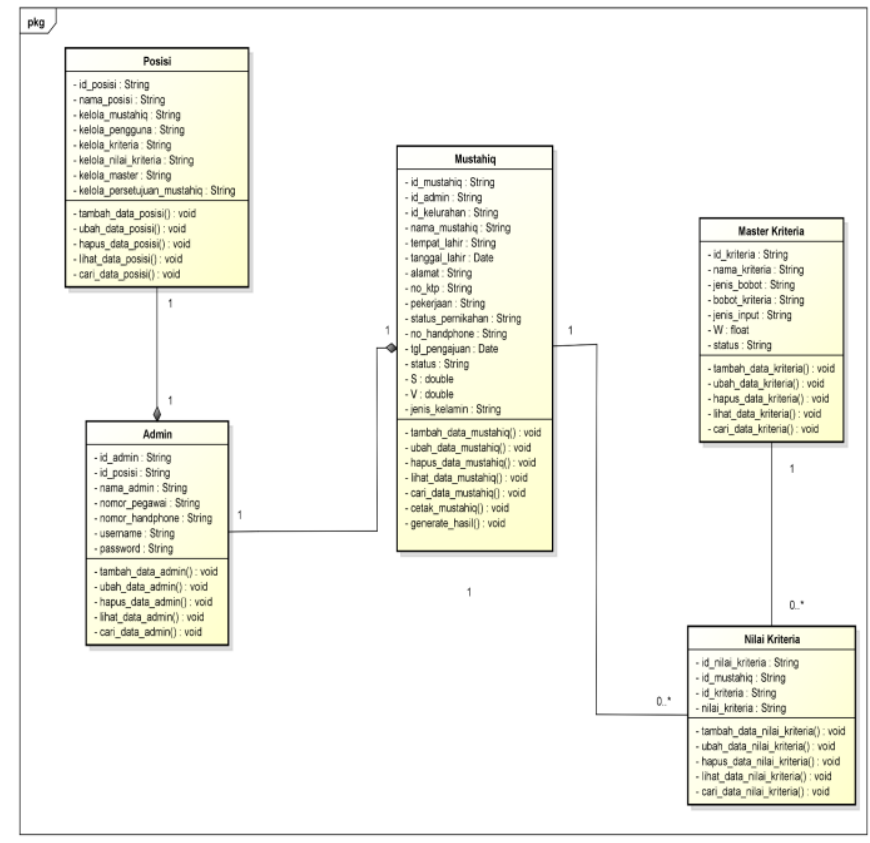

Gambar 7. Class diagram

\section{H. Perancangan Interface}

Tahap perancangan interface untuk memudahkan dalam merancang sistem pendukung keputusan penentu mustahik dengan membuat rancangan tampilan sistem. Gambar 8 merupakan rancangan antarmuka Sistem Pendukung Keputusan Penentu Mustahik pada Yayasan Qurrota Ayuni.

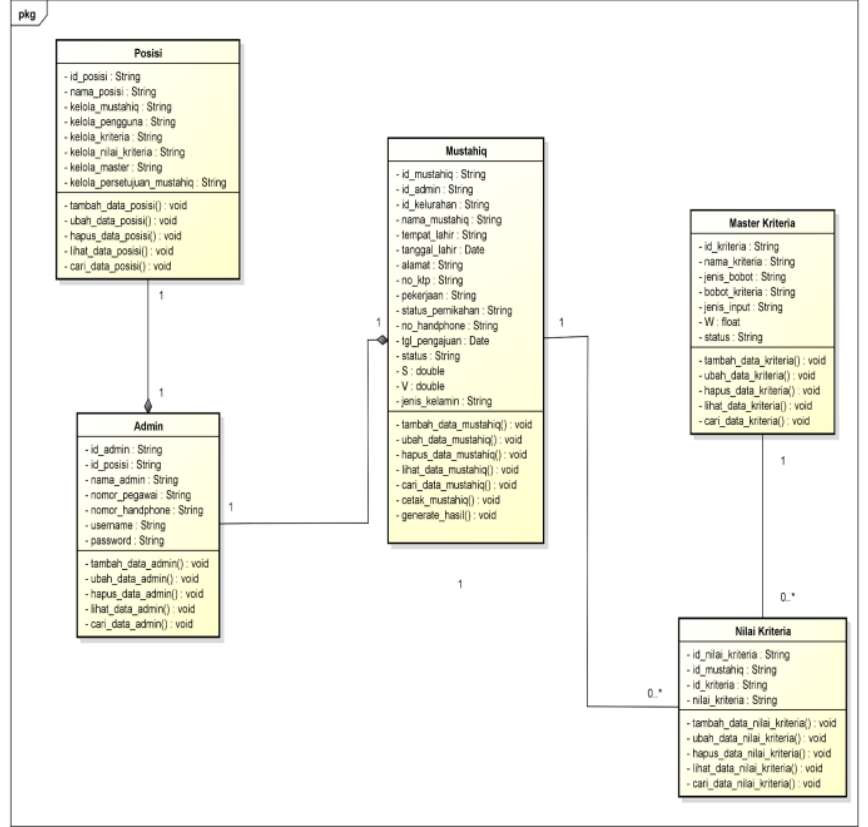

Gambar 8. Perancangan interface

\section{Pemrograman dan Arsitektur Hardware}

Pada pembuatan sistem pendukung keputusan ini menggunakan bahasa pemrograman PHP sedangkan database yang digunakan adalah MySQL. Perangkat keras yang digunakan agar dapat mendukung dalam implementasi sistem keputusan pendukung ini harus memiliki minimal spesifikasi sebagai berikut:
Prosesor : Intel I3
Memori : $2 \mathrm{~GB}$
Hardisk : $256 \mathrm{~GB}$
VGA Card : $512 \mathrm{MB}$

\section{J. Perangkat Lunak}

Perangkat lunak yang digunakan agar dapat mendukung dalam implementasi sistem pendukung keputusan penentu mustahik ini harus memiliki minimal spesifikasi sebagai berikut:

a. Microsoft windows 7;

b. Xampp yang mencakup MySQL;

c. Browser Google Chrome atau Mozilla Firefox.

\section{KESIMPULAN}

Berdasarkan hasil penelitian Sistem Pendukung Keputusan Penentu Mustahik dengan Metode Weighted Product pada Yayasan Qurrota Ayuni penulis membuat kesimpulan bahwa Sistem Pendukung Keputusan penentu Mustahik dengan metode Weighted Product pada Yayasan Qurrota Ayuni dibangun dengan menggunakan bahasa pemrograman PHP dan database MySQL. Metode pengembangan sistem yang digunakan yaitu Rapid Aplication Development. Secara fungsional Sistem Pendukung Keputusan Penentu Mustahik dengan Metode Weighted Product ini sudah menghasilkan

http://journal.uinjkt.ac.id/index.php/aism 
output yang diharapkan seperti hasil dari pengujian blackbox. Penelitian ini menghasilkan output laporan berupa daftar mustahik yang telah dihitung dan diurutkan menggunakan metode Weighted Product dengan kriteria pendapatan perbulan, jumlah tanggungan, kepemilikan rumah, kepemilikan kendaraan bermotor, ada tidaknya penanggung jawab dan kelengkapan berkas. SPK dapat dikembangkan dengan menerapkan keamanan data, berbasis android yang dapat diakses langsung dari smasrtphone dan mudah diakses. Penyempurnaan fungsi serta tampilan dari aplikasi sehingga sistem dapat semakin efektif dan efisien.

\section{REFERENSI}

[1] Yayasan Penyelenggara Penterjemah/Pentafsir Al Quran, "Al Muzzammil, 73: 20," Al Quran dan Terjemahnya,. Asy Syarif Medinah Munawwarah, 1990.

[2] Yayasan Penyelenggara Penterjemah/Pentafsir Al Quran, “Al Mu'minun, 23:1-4," Al Quran dan Terjemahnya,. Asy Syarif Medinah Munawwarah, 1990.

[3] Yayasan Penyelenggara Penterjemah/Pentafsir Al Quran, "At Taubah, 9:60," Al Quran dan Terjemahnya,. Asy Syarif Medinah Munawwarah, 1990.

[4] U. R. F. Averweg, Decision-Making Support Systems Theory \& practice, 2012.

[5] Basri. (2017). Metode Weighted Product (WP) dalam Sistem Pendukung Penerimaan Beasiswa Prestasi. Jurnal Insypro. [Online]. 2(1), pp. 1-6. Available: alauddin.ac.id/index.php/insypro/article/view/2474

[6] D. M. Khairina, D. Ivando, dan S. Maharani. (2016, Mei). Implementasi Metode Weighted Product untuk Aplikasi Pemilihan Smartphone Android. Jurnal Infotel. [Online]. 8(1), pp. 16-23. Available: https://ejournal.st3telkom.ac.id/index.php/infotel/article/view/47
[7] Suendri. (2018, Nopember). Implementasi Diagram UML (Unified Modelling Language) pada Perancangan Sistem Informasi Remunerasi Dosen dengan Database Oracle (Studi Kasus: UIN Sumatera Utara Medan). Jurnal Ilmu Komputer dan Informatika. [Online]. 3(1), pp. 1-9. Available:

http://jurnal.uinsu.ac.id/index.php/algoritma/article/view/3148

[8] Hendini. (2016, Desember). Pemodelan UML Sistem Informasi Monitoring Penjualan dan Stok Barang (Studi Kasus: Distro Zhezha Pontianak). Jurnal Khatulistiwa Informatika. [Online]. IV(2), pp. 107116. Available: https://ejournal.bsi.ac.id/ejurnal/index.php/khatulistiwa/article/view/126 2

[9] C. Budihartanti, Tuslaela, dan E. N. Aeni. (2019, Februari). Sistem Informasi Perpustakaan Online (E-Library) pada MTs Al Maghfiroh Pekayon. Jurnal Ilmu Pengetahuan dan Teknologi Komputer. [Online]. 4(2), pp. 245-250. Available: https://ejournal.nusamandiri.ac.id/index.php/jitk/article/view/304

[10] N. Irawati, H. D. E. Sinaga, dan A. Lubis. (2018, Juli). Sistem Pendukung Keputusan Penerimaan Dana BOS untuk Sekolah Dasar dengan Metode AHP (Dinas Pendidikan Kec. Sei Kepayang). Riau Journal of Computer Science. [Online]. 4(2), pp. 47-56. Available: https://ejournal.upp.ac.id/index.php/RJOCS/article/view/1630

[11] Y. Kristiawan, S. Siswanti dan W. L. Y. Saptomo. (2014). Sistem Pendukung Keputusan Investasi Perubaham dengan Metode Weighted Product Berbasis Sistem Informasi Geografi. Jurnal TiKomSiN. [Online]. 2(2), pp. 20-29. Available: https://p3m.sinus.ac.id/jurnal/index.php/TIKomSiN/article/view/168

[12] Republik Indonesia, Undang Undang Nomor 38 Tahun 1999, Pengelolaan Zakat, 23 Desember 1999.

[13] Gubernur Provinsi Banten, Peraturan Gubernur Provinsi Banten Nomor 4 Tahun 2004, Pengelolaan Zakat, 27 Desember 2004.

[14] K. E. Kendall dan J. E. Kendall, Analisa dan Perancangan Sistem. Jakarta: Indeks, 2010. 